\title{
REVIEW
}

\section{Drug repositioning for personalized medicine}

\author{
Yvonne Y Li and Steven JM Jones*
}

\begin{abstract}
Human diseases can be caused by complex mechanisms involving aberrations in numerous proteins and pathways. With recent advances in genomics, elucidating the molecular basis of disease on a personalized level has become an attainable goal. In many cases, relevant molecular targets will be identified for which approved drugs already exist, and the potential repositioning of these drugs to a new indication can be investigated. Repositioning is an accelerated route for drug discovery because existing drugs have established clinical and pharmacokinetic data. Personalized medicine and repositioning both aim to improve the productivity of current drug discovery pipelines, which expend enormous time and cost to develop new drugs, only to have them fail in clinical trials because of lack of efficacy or toxicity. Here, we discuss the current state of research in these two fields, focusing on recent large-scale efforts to systematically find repositioning candidates and elucidate individual disease mechanisms in cancer. We also discuss scenarios in which personalized drug repositioning could be particularly rewarding, such as for diseases that are rare or have specific mutations, as well as current challenges in this field. With an increasing number of drugs being approved for rare cancer subtypes, personalized medicine and repositioning approaches are poised to significantly alter the way we diagnose diseases, infer treatments and develop new drugs.
\end{abstract}

Keywords Personalized medicine, repositioning, repurposing, drug discovery, cancer, orphan diseases, high-throughput screening, computational drug design
*Correspondence: sjones@bcgsc.ca

Canada's Michael Smith Genome Sciences Centre, British Columbia Cancer Agency, Vancouver, British Columbia V5Z 4S6, Canada

\section{The importance of drug repositioning in the era of genomic medicine}

The perceived inefficiency of pharmaceutical drug development has been widely discussed [1-5]. Only 20 to 30 new chemical entities (NCEs: drugs not containing a previously approved active ingredient) are approved per year in the US [4], and each successful NCE requires an average of US $\$ 1.78$ billion and 13.5 years from discovery to market [5]. Although estimates of drug discovery costs vary (a recent study suggested that the minimum cost of developing an NCE is US\$204 million [6]), it is important to note that these estimates do not yet account for drug failures. Given that only $11 \%$ of drugs investigated in clinical trials are eventually approved [3], the actual cost of drug development is much higher than the published estimates.

Two approaches to improving productivity are rapidly gaining in popularity: drug repositioning to find new uses for existing drugs and personalized medicine to find tailored therapies for individual patients. The premise of repositioning is that reusing drugs that have previously passed clinical trials will minimize the risk of failure in future late-stage clinical trials due to toxicity and thus lead to faster drug approvals. Personalized medicine takes into account the fact that $30 \%$ of drugs investigated in clinical trials fail because of lack of efficacy [3], and its premise is that stratifying patients and diseases into molecular subtypes and treating with subtype-specific drugs will improve drug efficacy. The recent approval of crizotinib for non-small-cell lung cancer (NSCLC) provides a proof of concept for linking these two strategies: crizotinib was repositioned from anaplastic large-cell lymphoma treatment and is accompanied by a diagnostic test to identify the subset of NSCLC patients it is effective for [7]. Here, we introduce repositioning and personalized medicine approaches, discuss their benefits and challenges, and summarize recent studies that have propelled the fields forward.

\section{Drug repositioning as an efficient approach to drug discovery}

Drug repositioning is the process of finding new therapeutic indications for existing drugs. It can be an efficient approach to discovery because many existing drugs have 1) established formulations and manufacturing methods, 
2) extensive absorption distribution, metabolism, excretion and toxicity (ADMET) data, 3) previously passed clinical trial safety endpoints and are thus less likely to fail future clinical trials owing to adverse effects [2], and 4) phase IV (post-marketing surveillance) safety data, which are expensive and time consuming to obtain [8]. Reviews of the field indicate at least 46 approved drugs already repositioned for new therapeutic uses [2,9-11]. Examples discussed in this review are summarized in Table 1.

\section{Timeline of drug repositioning}

The standard drug discovery pipeline from target identification to drug approval is a 10 to 17 year process, comprising 2 to 3 years for target discovery and validation, 0.5 to 1 year to screen or design chemicals with biological activity, 1 to 3 years to optimize these drug leads using medicinal chemistry, 1 to 2 years to ascertain drug ADMET properties using animal models, 5 to 6 years to assess drug safety and efficacy in clinical trials, and 1 to 2 years to obtain approval [2].

Ashburn and Thor [2] estimated that repositioning could reduce the 10 to 17 year process to 3 to 12 years, because steps such as optimization and ADMET could be bypassed. Three drugs that have illustrated the accelerated timeline of repositioning are duloxetine, imatinib and crizotinib (Table 1). Duloxetine was originally developed to treat depression, but was first reported to improve stress urinary incontinence (SUI) outcomes in 1998 [12] and was then approved in Europe in 2004 [2]. Imatinib, which was developed for the treatment of chronic myeloid leukemia (CML), was first found to be effective in a single patient with gastrointestinal stromal tumor (GIST) in 2001 [13] and was approved by the US Food and Drug Administration (FDA) in 2008 [14]. Crizotinib has had the most rapid translation so far: the $E M L 4-A L K$ fusion was identified as an oncogene in NSCLC in August 2007 [15]; and the dual Met protooncogene/anaplastic lymphoma kinase (MET/ALK) inhibitor crizotinib, in clinical trials for anaplastic largecell lymphoma as a MET inhibitor, was then repositioned to NSCLC based on its ALK-inhibiting property; and it was approved for NSCLC treatment within just 4 years [7]. These timelines are much shorter than the 13.5 year average currently reported for new drugs [5] and highlight the efficiency of repositioning approaches.

\section{Types of drug repositioning}

Figure 1 summarizes various opportunities for repositioning. So far, most successfully repositioned drugs have been identified through serendipitous observations (Figure 1, path 1), such as the antiemetic thalidomide, which has gained new indications in leprosy and multiple myeloma [2].
Standard drug discovery strategies can also lead to repositioning opportunities. High-throughput screening detects compounds with biological activity, such as the inhibition of a disease phenotype (Figure 1, path 2) or target (path 3). Existing drugs found to potently modulate the desired activity are repositioning candidates. Gills et al. [16] tested six anti-HIV drugs against a panel of 60 cancer cell lines using cellular proliferation assays, and found nelfinavir to be a potent broad-spectrum antitumor agent. Nelfinavir has since entered at least eight cancer clinical trials [17]. Large-scale kinome assays have also been used to determine new targets of approved and clinically tested kinase inhibitors $[18,19]$. Other examples of drugs that have been repositioned based on novel target protein activity are shown in Table 1.

Repositioning can also occur when a new role is revealed for an existing target protein (path 4). The mammalian target of rapamycin (mTOR; a key protein controlling cell growth and division) and ALK (a membrane receptor tyrosine kinase involved in insulin signaling) were first identified as targets for immunosuppression and anaplastic large-cell lymphoma, respectively, but have since been identified as relevant therapeutic targets in pancreatic neuroendocrine tumors and NSCLC, respectively. These discoveries led to new indications for the mTOR inhibitor everolimus and the ALK inhibitor crizotinib $[7,20]$. Other examples are shown in Table 1.

The serotonin and norepinephrine reuptake inhibitor duloxetine is an example of repositioning at the pathway level (Figure 1, path 5). Duloxetine was first developed to treat depression; however, the finding that serotonin and norepinephrine signaling pathways were involved in spinal cord activation of the external urethral sphincter led to duloxetine being marketed for SUI [21]. Serotonin and norepinephrine were also found to be key neurotransmitters in fibromyalgia (a central nervous system disorder) and pain management; duloxetine has since been approved for fibromyalgia in 2008 [22] and for chronic musculoskeletal pain in 2010 [23].

Side effects observed in clinical trials that were not apparent in animal models may also lead to repositioning opportunities (path 6). Examples of drugs in this category include sildenafil and minoxidil, both of which were developed for hypertension but later became blockbuster drugs for erectile dysfunction and hair loss, respectively [24].

In some cases, repositioning avenues may already exist but have yet to be linked. The best known example is imatinib, which inhibits the BCR-ABL fusion protein (a constitutively active tyrosine kinase) in CML, but also potently inhibits v-kit oncogene homolog (KIT) and platelet-derived growth factor receptors (PDGFRs) [14]. Activating mutations in KIT and PDGFR- $\alpha$ (PDGFRA) are drivers of GIST proliferation. Connection of the 
Table 1. Examples of repositioned drugs, their targets and indications*

\begin{tabular}{|c|c|c|c|c|c|}
\hline Drug name & Original target & Original indication & New target & New indication & References \\
\hline \multicolumn{6}{|c|}{ Successful repositionings from approved drugs } \\
\hline Duloxetine & $\begin{array}{l}\text { Serotonin and } \\
\text { norepinephrine } \\
\text { reuptake }\end{array}$ & Depression & $\begin{array}{l}\text { Serotonin and } \\
\text { norepinephrine reuptake }\end{array}$ & $\begin{array}{l}\text { Stress urinary incontinence, } \\
\text { fibromyalgia, chronic } \\
\text { musculoskeletal pain }\end{array}$ & [12] \\
\hline Everolimus & mTOR & Immunosuppressant & Unchanged & $\begin{array}{l}\text { Pancreatic neuroendocrine } \\
\text { tumors }\end{array}$ & [20] \\
\hline Imatinib & BCR-ABL & CML & KIT, PDGFRA & GIST & [14] \\
\hline Minoxidil & Unknown & Hypertension & Unknown & Hair loss & [24] \\
\hline Nelfinavir & HIV-1 protease & AIDS & Inhibits AKT pathway & $\begin{array}{l}\text { In clinical trials for multiple } \\
\text { cancers }\end{array}$ & [17] \\
\hline Sildenafil & PDE5 & Angina & Unchanged & $\begin{array}{l}\text { Erectile dysfunction, } \\
\text { pulmonary arterial hypertension }\end{array}$ & $n^{[130]}$ \\
\hline Sunitinib & Multiple kinases & GIST, renal cell carcinoma & Unchanged & $\begin{array}{l}\text { Pancreatic neuroendocrine } \\
\text { tumors }\end{array}$ & [131] \\
\hline Trastuzumab & HER2 & HER2-positive breast cancer & Unchanged & $\begin{array}{l}\text { HER2-positive metastatic } \\
\text { gastric cancer }\end{array}$ & [129] \\
\hline \multicolumn{6}{|c|}{ Successful repositionings from investigational drugs } \\
\hline Crizotinib & MET kinase & $\begin{array}{l}\text { Clinical trials for anaplastic } \\
\text { large-cell lymphoma }\end{array}$ & EML4-ALK oncogene & NSCLC & [7] \\
\hline Thalidomide & Unknown & Morning sickness (withdrawn) & $\begin{array}{l}\text { Inhibits tumor necrosis } \\
\text { factor a production }\end{array}$ & Leprosy & [132] \\
\hline Thalidomide & Unknown & Morning sickness (withdrawn) & Inhibits angiogenesis & Multiple myeloma & [132] \\
\hline Zidovudine & Reverse transcriptase & Failed clinical trials for cancer & Reverse transcriptase & AIDS & [73] \\
\hline \multicolumn{6}{|c|}{ Unsuccessful repositionings } \\
\hline Bevacizumab & VEGF & Multiple cancers & Unchanged & $\begin{array}{l}\text { Failed clinical trial for gastric } \\
\text { cancer }\end{array}$ & [124] \\
\hline Buproprion & Unknown & Depression & $\begin{array}{l}\text { Synergistic inhibition of } \\
\text { appetite and energy } \\
\text { expenditure }\end{array}$ & $\begin{array}{l}\text { Obesity (rejected by FDA } \\
\text { owing to adverse effects) }\end{array}$ & {$[126,127]$} \\
\hline Naltrexone & Opioid receptors & Opioid addiction & $\begin{array}{l}\text { Synergistic inhibition of } \\
\text { appetite and energy } \\
\text { expenditure }\end{array}$ & $\begin{array}{l}\text { Obesity (rejected by FDA } \\
\text { owing to adverse effects) }\end{array}$ & {$[126,127]$} \\
\hline Naltrexone & Unknown & Alcohol dependence & $\begin{array}{l}\text { Synergistic inhibition of } \\
\text { appetite and energy } \\
\text { expenditure }\end{array}$ & $\begin{array}{l}\text { Obesity (rejected by FDA } \\
\text { owing to adverse effects) }\end{array}$ & {$[126,127]$} \\
\hline Sunitinib & Multiple kinases & GIST, renal cell carcinoma & Multiple kinases & $\begin{array}{l}\text { Failed clinical trials for } \\
\text { multiple cancers }\end{array}$ & [125] \\
\hline
\end{tabular}

*Drugs are divided into successful and unsuccessful repositionings. Within successful cases, drugs are further divided according to whether they were approved at their time of repositioning. For each drug, the original target and indication is listed, along with the new target and indication. In many cases, it can be seen that the new indication is still based on the same target protein. CML, chronic myeloid leukemia; GIST, gastrointestinal stromal tumor; NSCLC, non-small-cell lung cancer.

KIT-imatinib and KIT-GIST avenues in 1998 [25] led to FDA accelerated approval of imatinib in metastatic GISTs in 2002 [26] and regular approval in 2008 after clinical trials completion [14].

\section{Personalized medicine to reduce lack of drug efficacy}

The two foremost reasons for clinical drug attrition are inefficacy and toxicity. From 2008 to 2010, 51\% of 87 phase II drugs failed clinical trials because of inefficacy, and 19\% failed because of safety issues [27]. From 2007 to $2010,66 \%$ of 83 phase III drugs failed due to inefficacy and $21 \%$ because of safety issues [28]. Inadequacy of animal models is a factor in clinical trial failures [29], but two major reasons are disease and patient heterogeneity.

\section{Lack of efficacy due to disease heterogeneity}

The heterogeneity and complexity of human diseases has an important role in drug efficacy. For example, we now 


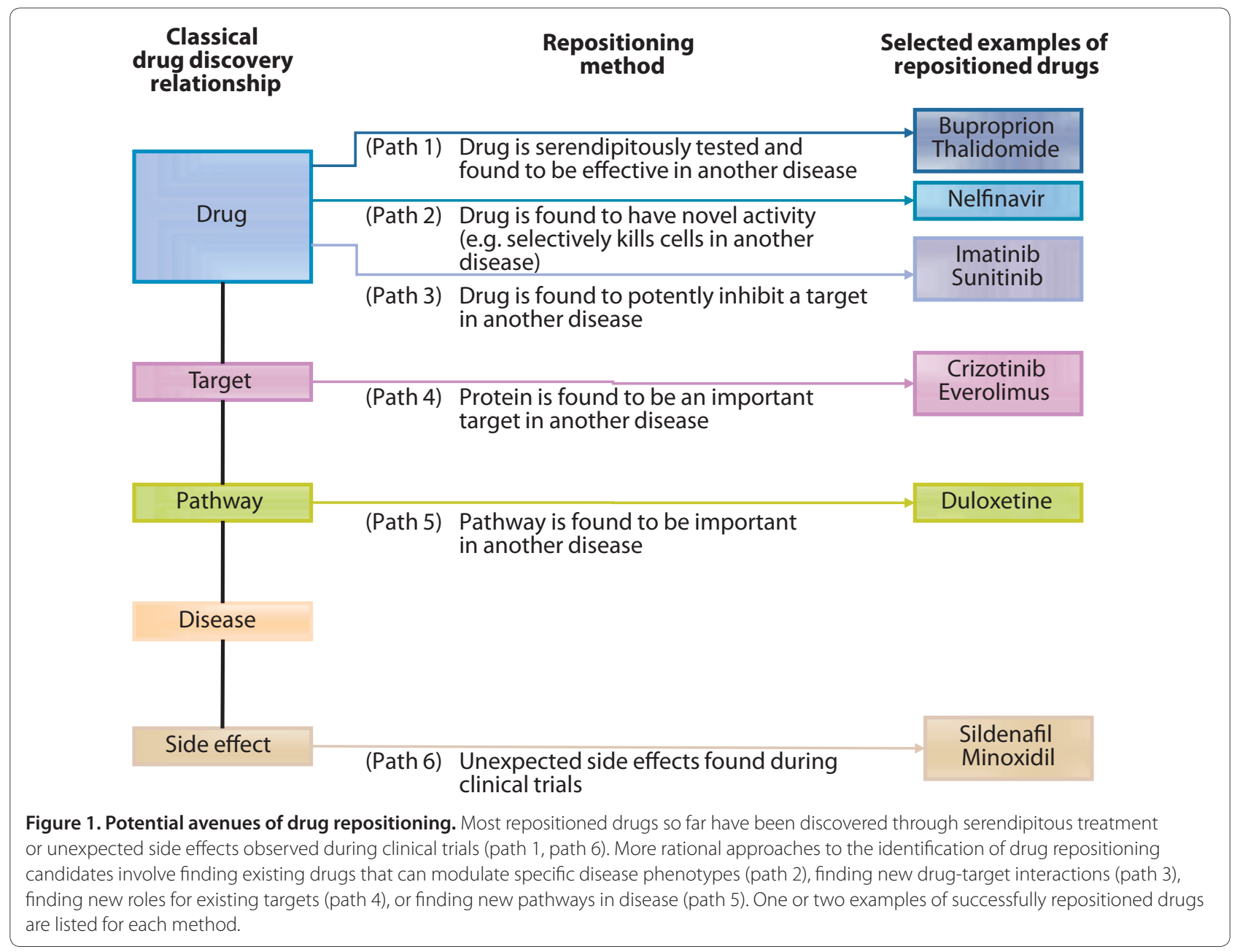

know that cancer is a collection of diseases and subtypes that are vastly different in their underlying molecular architecture. Gene expression profiles have classified breast tumors into four to six major subtypes [30,31] and diffuse large B-cell lymphomas into two to three major subtypes that respond differently to treatment [32]. There is also growing evidence for heterogeneity in many other diseases, from asthma [33] and diabetes [34] to less common disorders such as glycogen storage disease [35]. Specific oncogenic drivers have been elucidated for several rare cancer subtypes that aid in the interpretation of the heterogeneity, including the Philadelphia chromosome in 95\% cases of CML [14] (15\% of leukemias [36]), the EML4-ALK fusion driving 4 to $5 \%$ of NSCLC [37], and the RET proto-oncogene in familial medullary thyroid cancers (less than 3\% of thyroid cancers) [38].

In light of this disease heterogeneity, the aim of personalized medicine is to diagnose patients and prescribe drugs tailored to the molecular biology of the individual's disease. Various levels of molecular-level personalized medicine are already in place, such as the measurement of human epidermal growth factor receptor 2 (HER2) expression to determine whether breast cancer patients should receive trastuzumab therapy [39]. Patients being considered for anti-epidermal growth factor receptor (EGFR) therapy are often screened for mutations in the oncogene KRAS [40], because a constitutively active $K R A S$ gene downstream of EGFR would not be affected by EGFR inhibition. Gene profiling tests such as Oncotype Dx and MammaPrint predict the risk of recurrence of breast cancers to help guide treatment [41]. In August 2011, the FDA approved two drugs with companion diagnostic tests: vemurafenib with a PCR-based test for the V600E activating mutation in the oncoprotein BRAF in metastatic melanoma [42], and crizotinib with a fluorescence in situ hybridization (FISH)-based test to detect $A L K$ rearrangements in NSCLC [7]. Clearly, prescribing drugs only to a responsive subgroup of patients would improve the cost-effectiveness of the treatment. Appropriate molecular stratification would also result in candidate drugs being more likely to succeed in clinical trials instead of appearing ineffective 
because of the disease heterogeneity. But equally as important, the number of patients who would otherwise be prescribed an ineffective drug and experience adverse effects would decrease, and these patients would then have an opportunity to undertake other approved or experimental therapeutic regimens that might be beneficial.

\section{Lack of efficacy due to patient heterogeneity}

The variation of drug efficacy and toxicity between individuals is in part due to genetic polymorphisms in drug-metabolizing enzymes, drug transporters, receptors and other drug targets [43]. One of the earliest discovered examples is the enzyme thiopurine methyltransferase. Ten percent of Caucasians have intermediate activity and $0.33 \%$ have no activity in this enzyme, resulting in enhanced adverse effects when taking thiopurine drugs [44]. Another well known example is cytochrome 2D6 (CYP2D6), which metabolizes almost a quarter of prescription drugs. It has been reported that 7 to $14 \%$ of Caucasians carry a less efficient allele, and another $7 \%$ carry a highly efficient allele. Studies have shown that a patient's CYP2D6 genotype determines the effectiveness of tamoxifen treatment for estrogen-receptor-positive breast cancers [45]. Polymorphisms in ATP-binding cassette (ABC) drug transporters are also known to confer resistance to many drugs, including epilepsy drugs and fluvastatin [46]. Finally, a recent study found that $14 \%$ of pancreatic neuroendocrine tumors had mutations in mTOR pathway genes, which could affect the efficacy of the approved drug everolimus [47]. Resources such as PharmGKB [48] can be used to pinpoint genes that are known to be important in drug response, and the mutational statuses of those genes in the patient can be immediately reviewed.

Overall, a deeper understanding of patient and disease heterogeneity would allow us to better stratify patients in clinical trials and thus improve drug efficacy.

\section{Personalized genomic medicine}

Advances in whole genome sequencing (WGS), whole exome sequencing (WES) and whole transcriptome sequencing (RNA-seq) technologies now allow the examination of diseases in individual patients at an unprecedented resolution (Figure 2). Comparing a patient's tumor and normal genomes can comprehensively determine sequence, copy number, structural and expression aberrations in known disease genes. Any identified genes that already have approved targeted drugs used in other diseases could represent opportunities for repositioning. A few anecdotal cases in the literature highlight the potential of personalized genomics in diagnosing disease and inferring treatment. Gene expression profiling of a patient with an atypical morphology acute myeloid leukemia (AML) helped changed the treatment from standard AML-targeting drugs to rhabdomyosarcoma drugs [49]. Also, a large adaptive clinical trial tested NSCLC patients for 11 potential biomarkers and found that response to certain drugs or drug combinations correlated with specific markers [50].

The first report using sequencing to infer treatment was for a patient with a rare tongue adenocarcinoma and no standard treatment options. WGS and RNA-seq revealed amplification and upregulation of the RET proto-oncogene, and subsequent repositioning of RETinhibiting kinase drugs conferred 8 months of disease stabilization [51]. A metastatic tumor from this patient was sequenced after the disease progressed and was found to have 1) increased RET expression and downstream extracellular-signal-regulated kinase (ERK) expression and 2) increased expression in the parallel protein kinase $\mathrm{B}(\mathrm{AKT})$ pathway. This result suggested that a combination of AKT-pathway and ERK inhibitors could be effective in treating the metastasis [51]. In a second study, WGS confirmed that a patient with atypical AML and inconclusive FISH results had a pathogenic promyelocytic leukemia-retinoic acid receptor $\alpha(P M L-R A R A)$ gene fusion, which creates an oncogenic complex in AML. This confirmation led to all-trans retinoic acid consolidation treatment instead of a stem cell transplant [52]. Another study performed WES for a 15-month old boy, which revealed an X-linked inhibitor of apoptosis deficiency and led to recommendation for an allogeneic hematopoietic stem cell transplant [53]. Lastly, WGS, WES and RNA-seq on tumor and normal tissue from two patients with advanced or refractory cancer identified targetable oncogenes cyclin-dependent kinase 8 (CDK8) and neuroblastoma RAS viral oncogene homolog (NRAS) for the first patient and Harvey rat sarcoma viral oncogene homolog $(H R A S)$ for the second patient [54]. A multidisciplinary Sequencing Tumor Board concluded that the first patient should be treated with CDK or MEK inhibitors and the second patient with phosphoinositide3-kinase and MEK inhibitors [54].

Many targets do not yet have approved therapeutic options, such as the ERK and MEK targets identified in the above studies. In fact, only 364 of the 2,025 targets contained in the latest Therapeutic Target Database have approved drugs, another 286 have drugs in clinical trials, and the remaining 1,331 only have experimental inhibitors [55]. It is essential to have a repertoire of safe and effective small molecule modulators for all druggable targets so that therapeutic options will be available when a patient's disease is diagnosed at the molecular level. In the next few sections we discuss approaches to finding new interactions between therapeutic targets and approved drugs. 


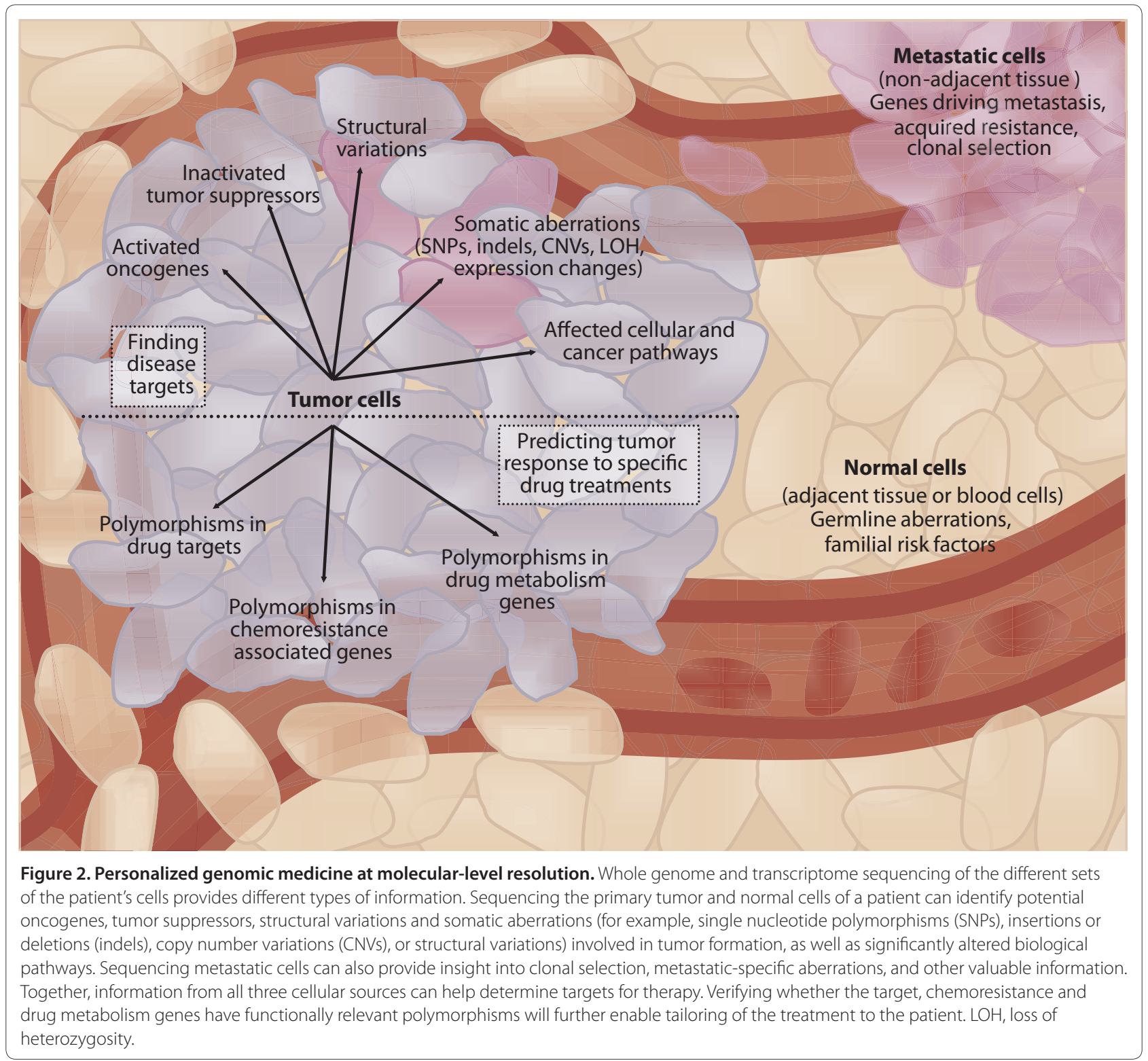

\section{Drug-target relationships: from the magic bullet to the multi-target paradigm}

In the late 19th century Paul Erlich first postulated the concept of 'magic bullets', or drugs that bind to a single molecular disease target [56]. This one-drug one-target one-disease strategy has driven much of drug discovery in the late 20th century and has resulted in successful targeted therapies. Well-known examples are the antibodies trastuzumab and rituximab and the small molecules imatinib and crizotinib (Table 1). However, we now know that small molecule drugs have extensive polypharmacologies, which may contribute to their clinical efficacy, or adverse effects or may provide insight into new repositioning opportunities.
Recent studies have evaluated the extent of polypharmacology by analyzing all known drug-target interactions. Paolini et al. [57] created a human pharmacology interaction network connecting proteins that share one or more chemical binders. In their database of 276,122 active compounds, 35\% hit more than one target, whereas $25 \%$ of the compounds bound targets from different protein families. In a second study, Mestres et al. [58] integrated seven drug-target interaction databases and found that, on average, each drug interacted with six different targets.

Protein kinase ATP-competitive inhibitors are the most extensive multi-targeting drugs known so far $[18,19]$, corresponding to the over 500 ATP-binding sites in the 
protein kinome [59]. Sunitinib used at concentrations of $10 \mu \mathrm{M}$ inhibited 79 of 119 kinases tested, although it had ten-fold stronger binding to its four intended targets than to any other off-target [18]. In contrast, vandetanib inhibited fewer kinases than sunitinib (50 of 119), but showed only two-fold stronger binding to its two intended targets [18].

There are many benefits to elucidating targets for a given drug. The first is to understand the clinically relevant polypharmacologies of a drug. For example, the schizophrenia drug clozapine unexpectedly showed less efficacy when chemical modifications were made to improve its target specificity [60]. In contrast, the serotonergic 5-hydroxytryptamine receptor 4 agonist cisapride, the histamine $\mathrm{H} 1$ receptor inhibitors astemizole and terfenadine, and the antibacterial drug grepafloxacin were withdrawn because of an increased risk of lifethreatening ventricular arrhythmias [61]. This adverse effect was determined to be due to inhibition of the human Ether-a-go-go-related gene (hERG) potassium channel, a key protein in cardiac repolarization and a target shared between these four chemically diverse drugs.

Understanding drug-target interactions also opens up the possibility of combining a number of approved drugs to enhance activity against a common therapeutic target, while minimizing effects on other targets. Moreover, using a combination of drugs may also provide a greater obstacle for a disease to acquire resistance. Many diseases have approved combination regimens, such as metastatic colorectal cancer and its four-drug FOLFIRI (folinic acid, 5-fluorouracil, irinotecan) with cetuximab regimen [62]. In short, finding all the targets of existing drugs is essential not only to understand their mode of action and their adverse effects but also to find repositioning opportunities.

\section{Current approaches to find new drug repositioning candidates}

Although the prospect of discovering specific multitargeting drugs is attractive, the actual implementation is a complicated endeavor. Drugs must be screened against multiple targets at a time and attain specific combinations of target affinities. In the case of sunitinib, it is still not clear exactly which combinations of its target inhibitions are effective for which cancers [63]. A more rational approach at present would be to determine new targets for existing drugs.

\section{Experimental approaches}

Experimental approaches to systematically elucidate new drug-target interactions fall into three categories. The first is to determine direct-binding partners of existing drugs. Examples of this approach include washing cell lysate extracts over a bead column fixed with an approved drug [64], high-throughput Biacore screening of an approved drug library against protein tyrosine phosphatase 1B [65], or high-throughput direct-binding assays to test drugs against 317 kinases [19]. In contrast, cellbased approaches screen for drugs that induce a desired change in cellular phenotype. They have been used to find approved drugs that can regulate autophagy [66], induce apoptosis in retinoblastoma cell lines [67], or inhibit proliferation of prostate cancer cell lines [68]. One recent study combined high-throughput cell proliferation, kinome binding assays and in vivo mouse studies to identify the chemotherapeutics 5 -fluorouracil and bortezomib as inhibitors of ependymoma (a chemoresistant brain tumor) and as leads for immediate clinical translation [69]. The third approach uses gene expression analysis to identify drugs that show an opposite gene expression profile to that of a disease [70], or that have similar gene expression profiles in cell lines to other approved drugs [71].

For experimental repositioning screens, obtaining a physical collection of approved drugs has been the greatest obstacle. Several companies have marketed smaller libraries containing 500 to 1,000 approved or off-patent drugs, including Enzi Life Sciences (Plymouth Meeting, PA, USA), Prestwick (Washington DC, USA), and Spectrum (Microsource, Gaylordsville, CT, USA). However, it was only in April 2011 that the National Institute of Health's Chemical Genomics Center (NCGC) pharmaceutical collection was initiated, containing 2,391 worldwide-approved drugs in a screenable format [72]. Their plan is to set up a screening service with collaborators and assess these drugs in a wide range of assays, and thus find new repositioning candidates for a wide range of diseases.

Aside from approved drugs, the multitude of compounds that have failed clinical trials because of lack of efficacy (not toxicity) also represent a rich resource for repositioning, as these drugs have known clinical and pharmacokinetic data. With results from personalized genomics studies underscoring the heterogeneity of diseases and patients, it is possible that many of these failed drugs were not tested on the correct subset of patients. Thus, failed drugs may still be useful for future personalized medicine approaches, particularly for those patients without other treatment options. For example, the ineffective cancer drug zidovudine later became a widely used anti-HIV drug [73]. A physical collection of failed compounds would be difficult to assemble because of the associated intellectual properties; however, we believe that this would be a valuable resource for both drug repositioning and personalized medicine.

\section{Computational approaches}

Given the large number of druggable protein targets and existing drugs, it is infeasible to set up assays to test every 
interaction in the laboratory. In addition to the time and cost required, a tailored assay must be developed for each protein, and compound libraries of all existing drugs must be collated. Many computational approaches have been published in recent years, many of which mirror the types of repositioning summarized in Figure 1. Most methods are based on similarity, between drugs [74], proteins [75], or side effect phenotypes [76]. These methods hypothesize that drugs with similar chemical structures or side effects are likely to have similar targets. A higher resolution method is molecular docking, which simulates the binding of a drug inside a target threedimensional structure at an atomic level. Docking is widely used to virtually screen large chemical libraries against targets of interest. In 2001, 'inverse docking' was first proposed as an approach for investigating the docking of one drug against multiple protein binding sites [77], and subsequent methods have been scaled up to investigate hundreds of targets and thousands of drugs [78-81]. However, the lack of solved protein structures for many targets is a major limitation of structure-based approaches.

Computational methods have also been applied to analyze the wealth of existing experimental data in public databases such as PubChem Bioassays [82] and the Gene Expression Omnibus [83]. New target-disease associations can also be formed using systems biology approaches [84]; in one study, network analysis identified a new glioblastoma target protein that already had an approved drug [85]. Furthermore, literature-mining methods used by mode of action by network analysis (MANTRA) [71], IDMap [86] and CoPub [87] can search for associations that already exist but have yet to be linked.

The most useful resources for computational methods are datasets of known interactions, often used as training data, positive control data or benchmark data in analyses. A few drug-target databases focusing on approved drugs include DrugBank, Kyoto Encyclopedia of Genes and Genomes (KEGG) Drug, the Therapeutic Target Database, and Matador [55,88-90]. Overall, computational efforts are efficient complementary approaches to experimental studies and have been described in more detail elsewhere [91,92].

\section{Applications of personalized medicine and drug repositioning}

The use of personalized medicine approaches to study individual diseases and reposition drugs for these diseases has far-reaching implications for diagnosis and treatment. Both of these methods are particularly relevant for rare diseases or disease subtypes, which are difficult to study and to hold clinical trials for owing to their low prevalence. They are also relevant for patients who are resistant to or have acquired resistance to therapies and do not have treatment options. In this section, we discuss how personalized medicine and drug repositioning strategies can be beneficial for these two scenarios.

\section{Rare diseases}

Orphan diseases are defined as diseases affecting a small percentage of the population (in the US, 'small' is defined as less than 1 in 200,000 people). However, despite the low prevalence, there are currently around 7,000 orphan diseases affecting approximately 25 million patients in North America. Approved drugs for rare cancer subtypes, such as crizotinib and imatinib, are the largest class of orphan disease drugs, representing $31 \%$ of all orphan products to date $[93,94]$.

Finding therapeutics for rare diseases may be particularly challenging as the low number of afflicted individuals and their geographical dispersal can render standard clinical trials infeasible [93]. It would thus be beneficial if approved drugs with existing safety profiles could be repositioned to an orphan disease. An example of this is sildenafil, which was first repositioned from the treatment of angina to erectile dysfunction, and has now received orphan drug approval for pulmonary arterial hypertension [95]. This strategy is supported by the observation that causative genes in many orphan diseases share pathways with common disease targets [96], creating opportunities for repositioning. The Rare Disease Repurposing Database currently lists 236 drugs that have shown clinical relevance for an orphan disease but are already marketed for at least one common disease [97].

Personalized genomic approaches are also particularly relevant for rare diseases, which often lack standard treatment options and can be difficult to diagnose. This was the case in the study mentioned above concerning a patient with a rare tongue adenocarcinoma and no standard treatment options [51]. An immunohistochemistry assay detected an EGFR amplification; however, treatment with the EGFR inhibitor erlotinib did not slow down tumor growth. Results from whole transcriptome shotgun sequencing and WGS revealed an increased copy number and gene expression of the RET oncogene, providing an explanation for the erlotinib inefficacy as well as pinpointing RET as a therapeutic target. The functional relevance of this pathway was verified when administration of RET-inhibiting drugs sunitinib and sorafenib stabilized the disease for 8 months. It would not have been possible to determine the functional relevance of all affected disease genes and set up a clinical trial for patients with the same subtype of cancer within a therapeutically relevant timeframe for this patient. Thus, personalized genomic approaches also represent a tractable method for rare diseases where low prevalence renders clinical trials infeasible. In extreme 
cases, a subset of patients may have molecular alterations that are unique or very rare and would thus need to be investigated individually [98]; elucidating these alterations would be the only way to accurately diagnose their diseases and recommend effective therapeutics. Furthermore, for highly heterogeneous diseases, clinical trials should be conducted in the context of the specific molecular defects and not the diseases.

Recent sequencing efforts have uncovered mutations in cancer genomes that appear at significant yet low frequencies, including mutations in genes encoding enhancer of zeste homolog 2, a histone-modifying enzyme [99], isocitrate dehydrogenase 1 (EZH2), an enzyme that creates an oncometabolite when mutated (IDH1) [100] and death-domain-associated protein (DAXX), thought to promote apoptosis [47] (more reviewed in [101]). Although the prospect of finding an existing drug that could selectively inhibit the identified variant is challenging, the potential time and money saved would be worth the investigatory high-throughput screens. In addition, modeling mutations in three dimensions (if a crystal structure of the target has been solved) would allow approved drugs to be readily screened in silico against the mutant and normal targets.

\section{Diseases that are resistant to treatment}

Acquired resistance is also a major obstacle to the effectiveness of current targeted therapies. Sequencing methods can be used to monitor patients undergoing treatment to detect the emergence of new mutations. The molecular pathways identified by genomic characterization of the primary disease can suggest personalized biomarkers with which to monitor the patient's disease progression. Metastasis genomes can be compared with previously characterized tumor and normal genomes to determine targetable pathways. Such analyses were performed in the previously mentioned investigation of a tongue adenocarcinoma patient, although studies of the post-treatment metastasis did not reveal molecular targets with approved therapeutic options [51].

Resistant disease may divide the molecular subtypes of the particular disease into even smaller groups, making rational drug repositioning more desirable. Also, resistant forms of disease may subsequently involve pathways for which there are obvious repositioning candidates. In short, personalized genomics approaches will be a powerful method to study individual drug resistance mechanisms, and repositioning will probably provide therapeutic options for these individual diseases.

\section{Challenges in personalized medicine and drug repositioning}

Personalized medicine at the molecular level is indeed a powerful tool to identify drugs tailored to an individual's disease. Recent studies have used sequencing approaches to characterize patient genomes; however, technologies to survey the proteome and epigenome and a better understanding of the interplay between genetics and the environment will be important additions to the personalized genomic diagnostic toolset. Today, we can sequence and analyze a cancer patient's low coverage whole genome (5 to 15X), transcriptome and exome (70 to 100X) for roughly US\$3,600 within 1 month [54] - a therapeutically relevant cost and timeframe. Moreover, the much-touted US $\$ 1,000$ genome is expected to be attained in 2012 [102].

However, there are still many factors that can complicate the process of personalized diagnosis and medicine. In this section, we discuss a number of the biological and analytical factors, including patient heterogeneity, tumor heterogeneity, acquired resistance, drug adverse effects, data interpretation and drug screening.

\section{Inter-patient heterogeneity}

The results of clinical trials show that approved targeted therapies for rare disease subtypes are not universally effective. The response rate of vemurafenib in patients with BRAF V600E-mutation-positive metastatic melanoma ranged from $48 \%$ to $52 \%$ [42]. Crizotinib had a $57 \%$ response rate in EML4- $A L K$-translocation-positive patients with NSCLC [103], and trastuzumab had only a 23\% response rate in HER2-positive metastatic breast cancer patients [104]. The substantial percentage of unresponsive patients suggests that important targets have yet to be discovered, which may further subdivide these diseases into more molecularly distinct subtypes.

\section{Intra-tumor heterogeneity}

Intra-tumor heterogeneity is the observation that tumors often contain unique cellular subpopulations, such as cancer stem cells, diverse subclones, as well as neighboring immune, stromal and normal cells. Sequencing mixtures of these cells may thus obfuscate details that are important for diagnosis or for determining drug combinations.

Intra-tumor heterogeneity also presents challenges to drug efficacy. For example, a study of eight AML patients with analysis of primary and relapse tumor genomes found that chemotherapy failed to eradicate all of the tumor subclones and the tumors acquired resistance to the drugs used [105]. This suggests that each tumor may even need to be stratified into distinct subclones and that the ideal treatment would be a combination of personalized, targeted therapies to eliminate all the subclones of individual tumors.

\section{Acquired resistance to targeted therapies}

Patients treated with crizotinib, vemurafenib or trastuzumab typically develop resistance within 1 year of 
treatment [106-108]. The mechanisms of resistance to targeted therapies vary between individuals [109] and can further stratify the disease. For example, tumors that acquired the same mutation that conferred imatinib resistance responded differently to increased doses of imatinib [110]. This result highlighted the intrinsic heterogeneity in resistant tumors, which could be due to the patient's genetic makeup. However, many cancers acquire resistance in predictable ways. For example, overexpression of PDGFR-beta (PDGFRB) and mutational activation of NRAS account for $40 \%$ of vemurafenib resistance cases in malignant myeloma [111]. Mutant ERK signaling was determined to be a resistance mechanism in another $30 \%$ of patients, suggesting that MEK inhibitors could be repositioned to treating these patients [112].

In CML, common mechanisms of imatinib resistance have also been identified, and the second-generation inhibitors dasatinib and nilotinib can target many $B C R$ $A B L$ mutations [113]. If we can identify the type of resistance mechanisms that a patient is likely to acquire, we could create drug combinations to reduce the chance of the disease acquiring resistance. For example, using an in vitro mutagenesis screen Bradeen et al. [114] determined that combination therapies of dasatinib plus imatinib or dasatinib plus nilotinib were able to eliminate the development of all but one acquired mutation in a CML cell line model. It is also conceivable that certain drugs could be used only to induce specific resistant forms of the disease, which could be treated effectively by subsequent drugs [115].

\section{Interpreting genomic data}

With rapidly increasing sequencing capacity, keeping up with analysis is a widely acknowledged problem [116]. Large computer clusters can be used for assembling and analyzing sequence data, but determining the germline or somatic aberrations that are driving the disease requires more attention. Databases such as Database for Annotation, Visualization and Integrated Discovery (DAVID) [117] and Ingenuity (Ingenuity Systems, Mountain View, CA, USA) map aberrations to known disease genes and pathways, but cannot accurately curate and interpret the entire available literature and incorporate this into their knowledge databases. Human expertise and research are necessary to fill gaps in existing databases and many factors can complicate diagnostic analyses. For example, if aberrations occur in multiple disease targets, determining which of the targets, if any, are of functional relevance to the disease may be impossible within a reasonable timeframe for the patient. Thus, the analyses are heavily reliant on the current state of the literature. It will be essential to discover more about the functions of all genes in the genome as well as their relevance to diseases to allow a better understanding of the observed aberrations. Similarly, a deeper understanding of the pharmacogenomic variants and drugdrug interactions in humans will allow us to better tailor therapies to individual patients. However, there will also be situations in which none of the disease targets identified have approved drugs, such as the 385 identified disease genes that do not yet have FDA-approved drugs [118]. Thus, the identification of new drug-target interactions is also essential to drug discovery.

\section{False positives and negatives in screening approaches}

Although we have reviewed many rational approaches to finding new interactions for existing drugs, highthroughput computational and experimental approaches each have their own sets of advantages and limitations [119-122]. False positive results can be detected in follow-up experiments and secondary screens, but false negative results are difficult to detect and can obstruct efforts to identify drug interactions when screening small libraries. The number of false negative results can be reduced with more replicate experiments and rigorous statistical analysis [123], or with a variation of biological assays (for example, testing in more cell lines), although these options will always be restricted by experimental time and cost. Ultimately, despite the goal of wholly rational drug design, serendipity still has a substantial role in finding new drug repositioning candidates.

\section{Failures in drug repositioning}

Not all cases of drug repositioning are successful. The kinase inhibitor bevacizumab failed to show efficacy in a phase III trial for gastric cancer despite having already been repositioned to many other cancers [124]. The multikinase inhibitor sunitinib has failed clinical trials for breast cancer, colorectal cancer, NSCLC and prostate cancer, but was approved for the treatment of GISTs, pancreatic neuroendocrine tumors and renal cell carcinomas among others [125]. The lack of efficacy of generic kinasetargeting drugs such as sunitinib suggests that, at least for some cancers, more targeted strategies need to be pursued.

The combination of bupropion and naltrexone, previously approved for the treatment of depression and opioid addiction, respectively, seemed to synergistically regulate appetite and energy expenditure in obesity [126]; however, the FDA rejected this combination in February 2011 owing to potential cardiovascular adverse effects [127]. Therefore, even repositioned drugs that have passed clinical safety standards might still be found to have adverse effects. In addition, it is important to consider the original drug indication during repositioning - for example, a cytotoxic chemotherapeutic may not be an ideal candidate for hypertension, as it may damage healthy cells at the required dosages. 


\section{Conclusions and future directions}

The field of medicine has always been personalized as doctors endeavor to determine the underlying causes of disease for each patient. However, with increasing biological knowledge and technologies, the resolution at which we can determine the contributing factors in disease has greatly improved. Human diseases are heterogeneous and complex, and sequencing methods now have the potential to characterize an individual's disease at a molecular resolution in clinically relevant timeframes. This can lead to treatments that take into account the specific molecular mechanisms underlying disease as well as the known pharmacogenomic variants in the patient. Some scientists now refer to this type of personalized medicine as 'precision medicine' [128].

Advances in next-generation sequencing technologies are enabling personalized genomic studies on a larger scale, which in turn provides insight into the heterogeneity between patients, within a disease and, in the case of cancer, even within a tumor. As personalized genomic studies gain in popularity and reveal molecular insights into diseases in individual patients, we will be able to segregate broad disease categories into smaller, target-centric subtypes, such as the EML4-ALK subtype of NSCLC and the BRAF V600E subtype of melanoma. The approval of trastuzumab for the treatment of a new HER2-positive subtype of gastric cancer is another example [129]. It will be essential to develop a toolkit of safe and effective drugs for the specific targets of such disease subtypes.

Given the considerable time and cost of developing new drugs, a much more efficient option is to reposition drugs from other disease indications when possible. These drugs are already approved for use in humans and are more likely to be safe than drugs still undergoing trials. In addition, approved drugs are already optimized to their target proteins, which is an advantage if the target is found to be important in another disease. However, if the drug is being repositioned to an offtarget's associated disease, the potent inhibition of the original target may cause adverse effects.

We have reviewed the various avenues in which repositioning can occur, as well as the experimental and virtual screening approaches that can be used to identify new drug-target interactions. Like personalized medicine, repositioning is also appropriate for rare diseases for which the recruitment of adequate numbers of patients for clinical trials is infeasible. In particular, repositioning approaches may find suitable drug candidates for disease targets with low-frequency mutations. To facilitate repositioning research, it is essential to have a physical collection of drugs for high-throughput screening. We have discussed some of these resources, such as the NCGC approved drug collection [72], and we suggest that a collection of the 27 to $45 \%$ of drugs that have failed clinical trials because of efficacy (89\% of drugs failed clinical trials, 30 to $50 \%$ because of lack of efficacy) $[3,27,28]$ would also be an excellent resource for repositioning. The spectrum of repositioned drugs discussed here shows that any type of drug, whether withdrawn (for example, thalidomide), in clinical trials (for example, crizotinib), failed in clinical trials (for example, zidovudine) or approved (for example, sunitinib), has the potential to be repositioned for treatment of another disease (Table 1). Drug repositioning analysis is likely to become routine for every new drug and target discovered, resulting in more efficient identification of therapeutics for targeting specific molecular aberrations.

The current de novo drug discovery pipeline is still essential for discovering and testing new drugs; however, stratification of patients based on their molecular disease signatures and testing of signature-targeting drugs should improve drug efficacies in clinical trials. For example, crizotinib would not have passed efficacy endpoints in a NSCLC trial as it is effective only in the 4 to $5 \%$ of patients with EML4-ALK translocations. Determining the appropriate biomarkers or clinical endpoints for assessing efficacy for each drug and implementing these in clinical trials is also a necessary step, but it will significantly increase the time and cost of clinical trials in the short term. Although there are still many challenges in drug repositioning and personalized medicine, we envision that comprehensive characterization of a person's genome and epigenome (whether by sequencing, proteome analysis or future technologies) will become a routine approach for diagnosing diseases and for recommending effective tailored medicines.

\section{Abbreviations}

ABC, ATP-binding cassette; ADMET, absorption, distribution, metabolism, excretion, toxicity; AKT, protein kinase B; ALK, anaplastic lymphoma kinase; BRAF, v-Raf murine sarcoma viral oncogene homolog B1; CDK8, cyclindependent kinase 8; CML, chronic myeloid leukemia; CYP2D6, cytochrome P450, family 2, subfamily D, polypeptide 6; EGFR, epidermal growth factor receptor; EML4, echinoderm microtubule associated protein like 4; ERK, extracellular-signal-regulated kinases; FDA, Food and Drug Administration; FISH, fluorescence in situ hybridization; FOLFIRI, folinic acid (leucovorin), 5-fluorouracil, irinotecan; GIST, gastrointestinal stromal tumor; KRAS, Kirsten rat sarcoma viral oncogene homolog; MANTRA, mode of action by network analysis; MEK, mitogen activating protein kinase/ERK kinase 1; MET, protooncogene c-Met (hepatocyte growth factor receptor); mTOR, mammalian target of rapamycin: NCGC, National Institute of Health Chemical Genomics Center; NCE, new chemical entity; NRAS, neuroblastoma RAS viral oncogene homolog; NSCLC, non-small-cell lung cancer; WES, whole exome sequencing: WGS, whole genome sequencing.

\section{Competing interests}

The authors declare that they have no competing interests.

\section{Acknowledgements}

We thank Katayoon Kasaian, Jianghong An and Erin Pleasance for their comments on the manuscript.

Published: 30 March 2012 


\section{References}

1. Lawrence S: Drug output slows in 2006. Nat Biotechnol 2007, 25:1073.

2. Ashburn TT, Thor KB: Drug repositioning: identifying and developing new uses for existing drugs. Nat Rev Drug Discov 2004, 3:673-683.

3. Kola I, Landis J: Can the pharmaceutical industry reduce attrition rates? Nat Rev Drug Discov 2004, 3:711-715.

4. Munos B: Lessons from 60 years of pharmaceutical innovation. Nat Rev Drug Discov 2009, 8:959-968.

5. Paul SM, Mytelka DS, Dunwiddie CT, Persinger CC, Munos BH, Lindborg SR, Schacht AL: How to improve R\&D productivity: the pharmaceutical industry's grand challenge. Nat Rev Drug Discov 2010, 9:203-214.

6. Light DW, Warburnt R: Demythologizing the high costs of pharmaceutical research. Biosoci 2011, 6:34-50

7. Shaw AT, Yasothan U, Kirkpatrick P: Crizotinib. Nat Rev Drug Discov 2011, 10:897-898

8. Tobinick EL: The value of drug repositioning in the current pharmaceutical market. Drug News Perspect 2009, 22:119-125

9. Chong CR, Sullivan DJ Jr: New uses for old drugs. Nature 2007, 448:645-646.

10. Smith RB: Repositioned drugs: integrating intellectual property and regulatory strategies. Drug Discov Today Ther Strateg 2011, 8:131.

11. Padhy BM, Gupta YK: Drug repositioning: re-investigating existing drugs for new therapeutic indications. J Postgrad Med 2011, 57:153-160.

12. Voelker R: International group seeks to dispel incontinence "taboo". JAMA 1998, 280:951-953.

13. Joensuu H, Roberts PJ, Sarlomo-Rikala M, Andersson LC, Tervahartiala P, Tuveson D, Silberman S, Capdeville R, Dimitrijevic S, Druker B, Demetri GD: Effect of the tyrosine kinase inhibitor STI571 in a patient with a metastatic gastrointestinal stromal tumor. N Engl J Med 2001, 344:1052-1056.

14. Druker B: Imatinib as a paradigm of targeted therapies. Adv Cancer Res 2004, 91:1- 30

15. Soda M, Choi YL, Enomoto M, Takada S, Yamashita Y, Ishikawa S, Fujiwara S, Watanabe H, Kurashina K, Hatanaka H, Bando M, Ohno S, Ishikawa Y, Aburatani H, Niki T, Sohara Y, Sugiyama Y, Mano H: Identification of the transforming EML4-ALK fusion gene in non-small-cell lung cancer. Nature 2007, 448:561-566.

16. Gills JJ, Lopiccolo J, Tsurutani J, Shoemaker RH, Best CJ, Abu-Asab MS, Borojerdi J, Warfel NA, Gardner ER, Danish M, Hollander MC, Kawabata S, Tsokos M, Figg WD, Steeg PS, Dennis PA: Nelfinavir, A lead HIV protease inhibitor, is a broad-spectrum, anticancer agent that induces endoplasmic reticulum stress, autophagy, and apoptosis in vitro and in vivo. Clin Cancer Res 2007, 13:5183-5194.

17. Chow WA, Jiang C, Guan M: Anti-HIV drugs for cancer therapeutics: back to the future? Lancet Oncol 2009, 10:61-71.

18. Fabian MA, Biggs WH 3rd, Treiber DK, Atteridge CE, Azimioara MD, Benedetti MG, Carter TA, Ciceri P, Edeen PT, Floyd M, Ford JM, Galvin M, Gerlach JL, Grotzfeld RM, Herrgard S, Insko DE, Insko MA, Lai AG, Lelias JM, Mehta SA, Milanov ZV, Velasco AM, Wodicka LM, Patel HK, Zarrinkar PP, Lockhart DJ: A small molecule-kinase interaction map for clinical kinase inhibitors. Nat Biotechno/ 2005, 23:329-336.

19. Karaman MW, Herrgard S, Treiber DK, Gallant P, Atteridge CE, Campbell BT Chan KW, Ciceri P, Davis MI, Edeen PT, Faraoni R, Floyd M, Hunt JP, Lockhart DJ, Milanov ZV, Morrison MJ, Pallares G, Patel HK, Pritchard S, Wodicka LM Zarrinkar PP: A quantitative analysis of kinase inhibitor selectivity. Nat Biotechnol 2008, 26:127-132.

20. FDA Okays Everolimus for Rare Type of Pancreatic Cancer [http://www.medscape.com/viewarticle/742274]

21. Schuessler B: What do we know about duloxetine's mode of action? Evidence from animals to humans. BJOG 2006, 113 Suppl 1:5-9.

22. Mease PJ: Further strategies for treating fibromyalgia: the role of serotonin and norepinephrine reuptake inhibitors. Am J Med 2009, 122(12 Suppl):S44-S55

23. Marcus DA: Duloxetine use in painful conditions. Expert Opin Pharmacother 2011, 12:1333-1340

24. Bradley D:Why big pharma needs to learn the three 'R's. Nat Rev Drug Discov 2005, 4:446.

25. Frantz S: Drug discovery: playing dirty. Nature 2005, 437:942-943.

26. Dagher R, Cohen M, Williams G, Rothmann M, Gobburu J, Robbie G, Rahman A, Chen G, Staten A, Griebel D, Pazdur R: Approval summary: imatinib mesylate in the treatment of metastatic and/or unresectable malignant gastrointestinal stromal tumors. Clin Cancer Res 2002, 8:3034-3038.

27. Arrowsmith J: Trial watch: Phase II failures: 2008-2010. Nat Rev Drug Discov
2011, 10:328-329.

28. Arrowsmith J: Trial watch: phase III and submission failures: 2007-2010. Nat Rev Drug Discov 2011, 10:87.

29. The bitterest pill. Nature 2006, 444:532-533.

30. Perou CM, Sorlie T, Eisen MB, van de Rijn M, Jeffrey SS, Rees CA, Pollack JR, Ross DT, Johnsen H, Akslen LA, Fluge O, Pergamenschikov A, Williams C, Zhu SX, Lonning PE, Borresen-Dale AL, Brown PO, Botstein D: Molecular portraits of human breast tumours. Nature 2000, 406:747-752.

31. Sorlie T, Perou CM, Tibshirani R, Aas T, Geisler S, Johnsen H, Hastie T, Eisen MB, van de Rijn M, Jeffrey SS, Thorsen T, Quist H, Matese JC, Brown PO, Botstein D, Eystein Lonning P, Borresen-Dale AL: Gene expression patterns of breast carcinomas distinguish tumor subclasses with clinical implications. Proc Natl Acad Sci U S A 2001, 98:10869-10874.

32. Lenz G, Wright G, Dave SS, Xiao W, Powell J, Zhao H, Xu W, Tan B, Goldschmidt N, labal J, Vose J, Bast M, Fu K, Weisenburger DD, Greiner TC, Armitage JO, Kyle A, May L, Gascoyne RD, Connors JM, Troen G, Holte H, Kvaloy S, Dierickx D, Verhoef G, Delabie J, Smeland EB, Jares P, Martinez A, Lopez-Guillermo A et al:: Stromal gene signatures in large-B-cell lymphomas. N Engl J Med 2008, 359:2313-2323

33. Borish L, Culp JA: Asthma: a syndrome composed of heterogeneous diseases. Ann Allergy Asthma Immunol 2008, 101:1-8; quiz 8-11, 50.

34. Pietropaolo M, Barinas-Mitchell E, Kuller LH: The heterogeneity of diabetes: unraveling a dispute: is systemic inflammation related to islet autoimmunity? Diabetes 2007, 56:1189-1197.

35. Shin YS: Glycogen storage disease: clinical, biochemical, and molecular heterogeneity. Semin Pediatr Neurol 2006, 13:115-120.

36. Faderl S, Talpaz M, Estrov Z, O'Brien S, Kurzrock R, Kantarjian HM: The biology of chronic myeloid leukemia. N Engl J Med 1999, 341:164-172.

37. Sasaki T, Rodig SJ, Chirieac LR, Janne PA: The biology and treatment of EML4-ALK non-small cell lung cancer. Eur J Cancer 2010, 46:1773-1780.

38. Roman S, Mehta P, Sosa JA: Medullary thyroid cancer: early detection and novel treatments. Curr Opin Oncol 2009, 21:5-10.

39. Ross JS: Saving lives with accurate HER2 testing. Am J Clin Patho/ 2010 134:183-184

40. Lefferts JA, Tsongalis GJ, Suriawinata AA, Funkhouser WK, Ladanyi M, Nowak JA, Pipas JM: KRAS mutation detection: a new look at an old gene. Clin Chem 2010, 56:698-701.

41. Drews J: Drug discovery: a historical perspective. Science 2000 287:1960-1964.

42. Flaherty KT, Yasothan U, Kirkpatrick P: Vemurafenib. Nat Rev Drug Discov 2011, 10:811-812.

43. Evans WE, Relling MV: Pharmacogenomics: translating functional genomics into rational therapeutics. Science 1999, 286:487-491.

44. McLeod HL, Siva C: The thiopurine S-methyltransferase gene locus implications for clinical pharmacogenomics. Pharmacogenomics 2002, 3:89-98

45. Goetz MP, Kamal A, Ames MM: Tamoxifen pharmacogenomics: the role of CYP2D6 as a predictor of drug response. Clin Pharmacol Ther 2008 83:160-166.

46. Sharom FJ: $A B C$ multidrug transporters: structure, function and role in chemoresistance. Pharmacogenomics 2008, 9:105-127.

47. Jiao Y, Shi C, Edil BH, de Wilde RF, Klimstra DS, Maitra A, Schulick RD, Tang LH, Wolfgang CL, Choti MA, Velculescu VE, Diaz LA Jr, Vogelstein B, Kinzler KW, Hruban RH, Papadopoulos N: DAXX/ATRX, MEN1, and mTOR pathway genes are frequently altered in pancreatic neuroendocrine tumors. Science 2011 331:1199-1203.

48. Altman RB: PharmGKB: a logical home for knowledge relating genotype to drug response phenotype. Nat Genet 2007, 39:426.

49. Golub TR, Slonim DK, Tamayo P, Huard C, Gaasenbeek M, Mesirov JP, Coller H, Loh ML, Downing JR, Caligiuri MA, Bloomfield CD, Lander ES: Molecular classification of cancer: class discovery and class prediction by gene expression monitoring. Science 1999, 286:531-537.

50. Anonymous: Trial watch: Adaptive BATTLE trial uses biomarkers to guide lung cancer treatment. Nat Rev Drug Discov 2010, 9:423.

51. Jones SJ, Laskin J, Li YY, Griffith OL, An J, Bilenky M, Butterfield YS, Cezard T, Chuah E, Corbett R, Fejes AP, Griffith M, Yee J, Martin M, Mayo M, Melnyk N, Morin RD, Pugh TJ, Severson T, Shah SP, Sutcliffe M, Tam A, Terry J, Thiessen N, Thomson T, Varhol R, Zeng T, Zhao Y, Moore RA, Huntsman DG, et al: Evolution of an adenocarcinoma in response to selection by targeted kinase inhibitors. Genome Bio/ 2010, 11:R82

52. Welch JS, Westervelt P, Ding L, Larson DE, Klco JM, Kulkarni S, Wallis J, Chen K, 
Payton JE, Fulton RS, Veizer J, Schmidt H, Vickery TL, Heath S, Watson MA, Tomasson MH, Link DC, Graubert TA, DiPersio JF, Mardis ER, Ley TJ, Wilson RK: Use of whole-genome sequencing to diagnose a cryptic fusion oncogene. JAMA 2011, 305:1577-1584.

53. Worthey EA, Mayer AN, Syverson GD, Helbling D, Bonacci BB, Decker B, Serpe JM, Dasu T, Tschannen MR, Veith RL, Basehore MJ, Broeckel U, Tomita-Mitchell A, Arca MJ, Casper JT, Margolis DA, Bick DP, Hessner MJ, Routes JM, Verbsky JW, Jacob HJ, Dimmock DP: Making a definitive diagnosis: successful clinical application of whole exome sequencing in a child with intractable inflammatory bowel disease. Genet Med 2011, 13:255-262.

54. Roychowdhury S, lyer MK, Robinson DR, Lonigro RJ, Wu YM, Cao X, KalyanaSundaram S, Sam L, Balbin OA, Quist MJ, Barrette T, Everett J, Siddiqui J, Kunju LP, Navone N, Araujo JC, Troncoso P, Logothetis CJ, Innis JW, Smith DC, Lao CD, Kim SY, Roberts JS, Gruber SB, Pienta KJ, Talpaz M, Chinnaiyan AM: Personalized oncology through integrative high-throughput sequencing: a pilot study. Sci Trans/ Med 2011, 3:111 ra121.

55. Zhu F, Shi Z, Qin C, Tao L, Liu X, Xu F, Zhang L, Song Y, Liu X, Zhang J, Han B, Zhang $P$, Chen $Y$ : Therapeutic target database update 2012: a resource for facilitating target-oriented drug discovery. Nucleic Acids Res 2011, 40:D1128-D1136.

56. Strebhardt K, Ullrich A: Paul Ehrlich's magic bullet concept: 100 years of progress. Nat Rev Cancer 2008, 8:473-480.

57. Paolini GV, Shapland RH, van Hoorn WP, Mason JS, Hopkins AL: Global mapping of pharmacological space. Nat Biotechnol 2006, 24:805-815.

58. Mestres J, Gregori-Puigjane E, Valverde S, Sole RV: The topology of drugtarget interaction networks: implicit dependence on drug properties and target families. Mol Biosyst 2009, 5:1051-1057.

59. Manning G, Whyte DB, Martinez R, Hunter T, Sudarsanam S: The protein kinase complement of the human genome. Science 2002, 298:1912-1934.

60. Roth BL, Sheffler DJ, Kroeze WK: Magic shotguns versus magic bullets: selectively non-selective drugs for mood disorders and schizophrenia. Nat Rev Drug Discov 2004, 3:353-359.

61. Du L, Li M, You Q, Xia L: A novel structure-based virtual screening model for the hERG channel blockers. Biochem Biophys Res Commun 2007, 355:889-894.

62. Van Cutsem E, Kohne CH, Lang I, Folprecht G, Nowacki MP, Cascinu S, Shchepotin I, Maurel J, Cunningham D, Tejpar S, Schlichting M, Zubel A, Celik I, Rougier P, Ciardiello F: Cetuximab plus irinotecan, fluorouracil, and leucovorin as first-line treatment for metastatic colorectal cancer: updated analysis of overall survival according to tumor KRAS and BRAF mutation status. J Clin Oncol 2011, 29:2011-2019.

63. Petrelli A, Giordano S: From single- to multi-target drugs in cancer therapy: when aspecificity becomes an advantage. Curr Med Chem 2008, 15:422-432.

64. Brehmer D, Greff Z, Godl K, Blencke S, Kurtenbach A, Weber M, Muller S, Klebl B, Cotten M, Keri G, Wissing J, Daub H: Cellular targets of gefitinib. Cancer Res 2005, 65:379-382

65. Zeder-Lutz G, Choulier L, Besse M, Cousido-Siah A, Figueras FX, Didier B, Jung $M L$, Podjarny A, Altschuh D: Validation of surface plasmon resonance screening of a diverse chemical library for the discovery of protein tyrosine phosphatase $1 \mathrm{~b}$ binders. Anal Biochem 2011, 421:417-427.

66. Zhang L, Yu J, Pan H, Hu P, Hao Y, Cai W, Zhu H, Yu AD, Xie X, Ma D, Yuan J: Small molecule regulators of autophagy identified by an image-based high-throughput screen. Proc Natl Acad Sci U S A 2007, 104:19023-19028.

67. Antczak C, Kloepping C, Radu C, Genski T, Muller-Kuhrt L, Siems K, de Stanchina E, Abramson DH, Djaballah H: Revisiting old drugs as novel agents for retinoblastoma: in vitro and in vivo antitumor activity of cardenolides. Invest Ophthalmol Vis Sci 2009, 50:3065-3073.

68. Iljin K, Ketola K, Vainio P, Halonen P, Kohonen P, Fey V, Grafstrom RC, Perala M, Kallioniemi O: High-throughput cell-based screening of 4910 known drugs and drug-like small molecules identifies disulfiram as an inhibitor of prostate cancer cell growth. Clin Cancer Res 2009, 15:6070-6078.

69. Atkinson JM, Shelat AA, Carcaboso AM, Kranenburg TA, Arnold LA, Boulos N, Wright K, Johnson RA, Poppleton H, Mohankumar KM, Feau C, Phoenix T, Gibson P, Zhu L, Tong Y, Eden C, Ellison DW, Priebe W, Koul D, Yung WK, Gajjar A, Stewart CF, Guy RK, Gilbertson RJ: An integrated in vitro and in vivo highthroughput screen identifies treatment leads for ependymoma. Cancer Cell 2011, 20:384-399.

70. Lamb J, Crawford ED, Peck D, Modell JW, Blat IC, Wrobel MJ, Lerner J, Brunet JP, Subramanian A, Ross KN, Reich M, Hieronymus H, Wei G, Armstrong SA, Haggarty SJ, Clemons PA, Wei R, Carr SA, Lander ES, Golub TR: The Connectivity Map: using gene-expression signatures to connect small molecules, genes, and disease. Science 2006, 313:1929-1935

71. Iorio F, Bosotti R, Scacheri E, Belcastro V, Mithbaokar P, Ferriero R, Murino L, Tagliaferri R, Brunetti-Pierri N, Isacchi A, di Bernardo D: Discovery of drug mode of action and drug repositioning from transcriptional responses. Proc Natl Acad Sci U S A 2010, 107:14621-14626.

72. Huang R, Southall N, Wang Y, Yasgar A, Shinn P, Jadhav A, Nguyen DT, Austin CP: The NCGC pharmaceutical collection: a comprehensive resource of clinically approved drugs enabling repurposing and chemical genomics. SciTrans/ Med 2011, 3:80ps16.

73. Broder S: The development of antiretroviral therapy and its impact on the HIV-1/AIDS pandemic. Antiviral Res 2010, 85:1-18.

74. Keiser MJ, Setola V, Irwin JJ, Laggner C, Abbas Al, Hufeisen SJ, Jensen NH, Kuijer MB, Matos RC, Tran TB, Whaley R, Glennon RA, Hert J, Thomas KL, Edwards DD, Shoichet BK, Roth BL: Predicting new molecular targets for known drugs. Nature 2009, 462:175-181.

75. Kinnings SL, Liu N, Buchmeier N, Tonge PJ, Xie L, Bourne PE: Drug discovery using chemical systems biology: repositioning the safe medicine Comtan to treat multi-drug and extensively drug resistant tuberculosis. PLOS Comput Biol 2009, 5:e1000423.

76. Campillos M, Kuhn M, Gavin AC, Jensen LJ, Bork P: Drug target identification using side-effect similarity. Science 2008, 321:263-266.

77. Chen YZ, Zhi DG: Ligand-protein inverse docking and its potential use in the computer search of protein targets of a small molecule. Proteins 2001, 43:217-226.

78. Yang L, Chen J, Shi L, Hudock MP, Wang K, He L: Identifying unexpected therapeutic targets via chemical-protein interactome. PLoS One 2010, 5:e9568.

79. Li H, Gao Z, Kang L, Zhang H, Yang K, Yu K, Luo X, Zhu W, Chen K, Shen J, Wang $X$, Jiang H: TarFisDock: a web server for identifying drug targets with docking approach. Nucleic Acids Res 2006, 34:W219-W224.

80. Li L B Bum-Erdene K, Baenziger PH, Rosen Jل, Hemmert JR, Nellis JA, Pierce ME, Meroueh SO: BioDrugScreen: a computational drug design resource for ranking molecules docked to the human proteome. Nucleic Acids Res 2010, 38:D765-D773

81. Li YY, An J, Jones SJ: A computational approach to finding novel targets for existing drugs. PLoS Comput Biol 2011, 7:e1002139.

82. Chen B, Wild D, Guha R: PubChem as a source of polypharmacology. J Chem Inf Model 2009, 49:2044-2055.

83. Dudley JT, Sirota M, Shenoy M, Pai RK, Roedder S, Chiang AP, Morgan AA, Sarwal MM, Pasricha PJ, Butte AJ: Computational repositioning of the anticonvulsant topiramate for inflammatory bowel disease. Sci Trans/ Med 2011, 3:96ra76.

84. Pujol A, Mosca R, Farres J, Aloy P: Unveiling the role of network and systems biology in drug discovery. Trends Pharmacol Sci 2010, 31:115-123.

85. Kotelnikova E, Yuryev A, Mazo I, Daraselia N: Computational approaches for drug repositioning and combination therapy design. J Bioinform Comput Biol 2010, 8:593-606.

86. Ha S, Seo YJ, Kwon MS, Chang BH, Han CK, Yoon JH: IDMap: facilitating the detection of potential leads with therapeutic targets. Bioinformatics 2008, 24:1413-1415.

87. Frijters $R$, van Vugt M, Smeets $R$, van Schaik R, de Vlieg J, Alkema W: Literature mining for the discovery of hidden connections between drugs, genes and diseases. PLoS Comput Biol 2010, 6:e1000943.

88. Wishart DS, Knox C, Guo AC, Shrivastava S, Hassanali M, Stothard P, Chang Z, Woolsey J: DrugBank: a comprehensive resource for in silico drug discovery and exploration. Nucleic Acids Res 2006, 34:D668-D672.

89. Kanehisa M, Goto S, Hattori M, Aoki-Kinoshita KF, Itoh M, Kawashima S, Katayama T, Araki M, Hirakawa M: From genomics to chemical genomics: new developments in KEGG. Nucleic Acids Res 2006, 34:D354-D357.

90. Gunther S, Kuhn M, Dunkel M, Campillos M, Senger C, Petsalaki E, Ahmed J, Urdiales EG, Gewiess A, Jensen LJ, Schneider R, Skoblo R, Russell RB, Bourne $P E$, Bork P, Preissner R: SuperTarget and Matador: resources for exploring drug-target relationships. Nucleic Acids Res 2008, 36:D919-D922.

91. Dudley JT, Deshpande T, Butte AJ: Exploiting drug-disease relationships for computational drug repositioning. Brief Bioinform 2011, 12:303-311.

92. Haupt VJ, Schroeder M: Old friends in new guise: repositioning of known drugs with structural bioinformatics. Brief Bioinform 2011, 12:312-326.

93. Haffner ME: Adopting orphan drugs - two dozen years of treating rare diseases. N Engl J Med 2006, 354:445-447.

94. Cote TR, Xu K, Pariser AR: Accelerating orphan drug development. Nat Rev Drug Discov 2010, 9:901-902. 
95. Tambuyzer E: Rare diseases, orphan drugs and their regulation: questions and misconceptions. Nat Rev Drug Discov 2010, 9:921-929.

96. Sardana D, Zhu C, Zhang M, Gudivada RC, Yang L, Jegga AG: Drug repositioning for orphan diseases. Brief Bioinform 2011, 12:346-356.

97. Xu K, Cote TR: Database identifies FDA-approved drugs with potential to be repurposed for treatment of orphan diseases. Brief Bioinform 2011, 12:341-345

98. La Thangue NB, Kerr DJ: Predictive biomarkers: a paradigm shift towards personalized cancer medicine. Nat Rev Clin Oncol 2011, 8:587-596.

99. Morin RD, Johnson NA, Severson TM, Mungall AJ, An J, Goya R, Paul JE, Boyle M, Woolcock BW, Kuchenbauer F, Yap D, Humphries RK, Griffith OL, Shah S, Zhu H, Kimbara M, Shashkin P, Charlot JF, Tcherpakov M, Corbett R, Tam A, Varhol R, Smailus D, Moksa M, Zhao Y, Delaney A, Qian H, Birol I, Schein J, Moore R, et al:: Somatic mutations altering EZH2 (Tyr641) in follicular and diffuse large B-cell lymphomas of germinal-center origin. Nat Genet 2010, 42:181-185.

100. Mardis ER, Ding L, Dooling DJ, Larson DE, McLellan MD, Chen K, Koboldt DC, Fulton RS, Delehaunty KD, McGrath SD, Fulton LA, Locke DP, Magrini VJ, Abbott RM, Vickery TL, Reed JS, Robinson JS, Wylie T, Smith SM, Carmichael L, Eldred JM, Harris CC, Walker J, Peck JB, Du F, Dukes AF, Sanderson GE, Brummett AM, Clark E, McMichael JF, et al:: Recurring mutations found by sequencing an acute myeloid leukemia genome. N Engl J Med 2009, 361:1058-1066

101. Stratton MR: Exploring the genomes of cancer cells: progress and promise. Science 2011, 331:1553-1558

102. Sinha G: Academia's \$1,000 genome. Nat Biotechnol 2011, 29:960-960a.

103. Hallberg B, Palmer RH: Crizotinib - latest champion in the cancer wars? N Engl J Med 2010, 363:1760-1762.

104. Vogel CL, Cobleigh MA, Tripathy D, Gutheil JC, Harris LN, Fehrenbacher L, Slamon DJ, Murphy M, Novotny WF, Burchmore M, Shak S, Stewart SJ, Press M: Efficacy and safety of trastuzumab as a single agent in first-line treatment of HER2-overexpressing metastatic breast cancer. J Clin Oncol 2002, 20:719-726.

105. Ding L, Ley TJ, Larson DE, Miller CA, Koboldt DC, Welch JS, Ritchey JK, Young MA, Lamprecht T, McLellan MD, McMichael JF, Wallis JW, Lu C, Shen D, Harris CC, Dooling DJ, Fulton RS, Fulton LL, Chen K, Schmidt H, Kalicki-Veizer J, Magrini VJ, Cook L, McGrath SD, Vickery TL, Wendl MC, Heath S, Watson MA et al:: Clonal evolution in relapsed acute myeloid leukaemia revealed by whole-genome sequencing. Nature 2012, 481:506-510,

106. Nahta R, Esteva FJ: HER2 therapy: molecular mechanisms of trastuzumab resistance. Breast Cancer Res 2006, 8:215

107. Solit D, Sawyers CL: Drug discovery: How melanomas bypass new therapy. Nature 2010, 468:902-903.

108. Katayama R, Shaw AT, Khan TM, Mino-Kenudson M, Solomon BJ, Halmos B, Jessop NA, Wain JC, Yeo AT, Benes C, Drew L, Saeh JC, Crosby K, Sequist LV, lafrate AJ, Engelman JA: Mechanisms of acquired crizotinib resistance in ALK-rearranged lung cancers. Sci Trans/Med 2012, 4:120ra17.

109. Batist G, Wu JH, Spatz A, Miller WH Jr, Cocolakis E, Rousseau C, Diaz Z, Ferrario C, Basik M: Resistance to cancer treatment: the role of somatic genetic events and the challenges for targeted therapies. Front Pharmaco/ 2011 2:59.

110. Khorashad JS, Anand M, Marin D, Saunders S, Al-Jabary T, Iqbal A, Margerison S, Melo JV, Goldman JM, Apperley JF, Kaeda J: The presence of a BCR-ABL mutant allele in CML does not always explain clinical resistance to imatinib. Leukemia 2006, 20:658-663.

111. Nazarian R, Shi H, Wang Q, Kong X, Koya RC, Lee H, Chen Z, Lee MK, Attar N, Sazegar H, Chodon T, Nelson SF, McArthur G, Sosman JA, Ribas A, Lo RS: Melanomas acquire resistance to B-RAF(V600E) inhibition by RTK or N-RAS upregulation. Nature 2010, 468:973-977.

112. Poulikakos PI, Persaud Y, Janakiraman M, Kong X, Ng C, Moriceau G, Shi H, Atefi M, Titz B, Gabay MT, Salton M, Dahlman KB, Tadi M, Wargo JA, Flaherty KT, Kelley MC, Misteli T, Chapman PB, Sosman JA, Graeber TG, Ribas A, Lo RS, Rosen N, Solit DB: RAF inhibitor resistance is mediated by dimerization of aberrantly spliced BRAF(V600E). Nature 2011, 480:387-390.
113. Milojkovic D, Apperley J: Mechanisms of resistance to imatinib and secondgeneration tyrosine inhibitors in chronic myeloid leukemia. Clin Cancer Res 2009, 15:7519-7527.

114. Bradeen HA, Eide CA, O'Hare T, Johnson KJ, Willis SG, Lee FY, Druker BJ, Deininger MW: Comparison of imatinib mesylate, dasatinib (BMS-354825), and nilotinib (AMN107) in an N-ethyl-N-nitrosourea (ENU)-based mutagenesis screen: high efficacy of drug combinations. Blood 2006, 108:2332-2338.

115. Kasaian K, Jones SJ: A new frontier in personalized cancer therapy: mapping molecular changes. Future Oncol 2011, 7:873-894.

116. Gross M: Riding the wave of biological data. Curr Bio/ 2011, 21:R204-R206.

117. Huang da W, Sherman BT, Tan Q, Kir J, Liu D, Bryant D, Guo Y, Stephens R, Baseler MW, Lane HC, Lempicki RA: DAVID Bioinformatics Resources: expanded annotation database and novel algorithms to better extract biology from large gene lists. Nucleic Acids Res 2007, 35:W169-W175.

118. Sakharkar MK, Li P, Zhong Z, Sakharkar KR: Quantitative analysis on the characteristics of targets with FDA approved drugs. Int J Bio/ Sci 2007, 4:15-22.

119. Shoichet BK: Screening in a spirit haunted world. Drug Discov Today 2006 11:607-615.

120. Parker CN, Bajorath J: Towards unified compound screening strategies: a critical evaluation of error sources in experimental and virtual highthroughput screening. QSAR Combinatorial Sci 2006, 25:1153-1161.

121. Crisman TJ, Parker CN, Jenkins JL, Scheiber J, Thoma M, Kang ZB, Kim R, Bender A, Nettles JH, Davies JW, Glick M: Understanding false positives in reporter gene assays: in silico chemogenomics approaches to prioritize cell-based HTS data. J Chem Inf Model 2007, 47:1319-1327.

122. Klebe $\mathrm{G}$ : Virtual ligand screening: strategies, perspectives and limitations. Drug Discov Today 2006, 11:580-594.

123. Malo N, Hanley JA, Cerquozzi S, Pelletier J, Nadon R: Statistical practice in high-throughput screening data analysis. Nat Biotechno/ 2006, 24:167-175.

124. Kang H, Kauh JS: Chemotherapy in the treatment of metastatic gastric cancer: is there a global standard? Curr Treat Options Oncol 2011, 12:96-106.

125. FDA Expands Sutent Label to Include Pancreatic Neuroendocrine Tumors. GEN News Highlights 23 May 2011.

[http://www.genengnews.com/gen-news-highlights/

fda-expands-sutent-label-to-include-pancreatic-neuroendocrinetumors/81245191/

126. Plodkowski RA, Nguyen Q, Sundaram U, Nguyen L, Chau DL, St Jeor S: Bupropion and naltrexone: a review of their use individually and in combination for the treatment of obesity. Expert Opin Pharmacother 2009, 10:1069-1081.

127. Caveney E, Caveney BJ, Somaratne R, Turner JR, Gourgiotis L: Pharmaceutical interventions for obesity: a public health perspective. Diabetes Obes Metab 2011, 13:490-497.

128. Mirnezami R, Nicholson J, Darzi A: Preparing for precision medicine. N Engl J Med 2012, 366:489-491

129. Rose JS, Bekaii-Saab TS: New developments in the treatment of metastatic gastric cancer: focus on trastuzumab. Onco Targets Ther 2011, 4:21-26.

130. Ghofrani HA, Osterloh $H$, Grimminger F: Sildenafil: from angina to erectile dysfunction to pulmonary hypertension and beyond. Nat Rev Drug Discov 2006, 5:689-702

131. Delbaldo C, Faivre S, Dreyer C, Raymond E: Sunitinib in advanced pancreatic neuroendocrine tumors: latest evidence and clinical potential. Ther $A d v$ Med Oncol 2012, 4:9-18.

132. Paravar T, Lee DJ: Thalidomide: mechanisms of action. Int Rev Immuno/ 2008 , 27:111-135.

doi:10.1186/gm326

Cite this article as: LiYY, Jones SJM: Drug repositioning for personalized

medicine. Genome Medicine 2012, 4:27. 